\title{
LA LEY DE LA CADENA ALIMENTARIA Y SU MODIFICACIÓN. PRINCIPALES IMPLICACIONES SOBRE LAS COOPERATIVAS AGROALIMENTARIAS.
}

\author{
Juan Fco. Juliá*, Felipe Palau, Elena Meliá, Eduardo Miranda.
}

\author{
CEGEA. Universitat Politècnica de València.
}

\begin{abstract}
Resumen:
La Cadena de Valor Agroalimentaria conformada por el llamado sector agroalimentario ampliado en el que se integran la producción, la industria transformadora, y los distintos operadores comerciales incluida la distribución, constituye hoy sin duda un sector estratégico de la economía española. Pero pese a ello, al igual que el conjunto del sector en la UE27, adolece de diversos problemas estructurales y operativos, y especialmente de una importante asimetría entre sus distintos eslabones que ya viene de décadas (Lamo de Espinosa 1990, Batzeli 2009, Bijman 2013), lo que conduce, en ocasiones, a una asignación de precios injusta, que perjudica a los más débiles, que, en general, suelen ser los agricultores y ganaderos. La presente comunicación viene motivada por la publicación del Proyecto de Ley por el que se modifica la Ley 12/2013, de 2 de agosto, de medidas para mejorar el funcionamiento de la cadena alimentaria. Tanto la Ley como el Proyecto de Ley regulan diferentes aspectos que afectan a las sociedades cooperativas y plantean interrogantes que pueden generarles un perjuicio si no se resuelven adecuadamente. Concretamente, nos estamos refiriendo a la necesidad de determinar un procedimiento para calcular el valor del producto entregado por parte del socio a la cooperativa y la obligatoriedad de abonar el coste efectivo de producción al operador inmediatamente anterior, en este caso de la cooperativa al socio. De manera que, la presente comunicación se centrará en analizar estas disposiciones, con el objetivo de tratar de aportar soluciones ante las diferentes incógnitas planteadas.
\end{abstract}

Palabras clave: Cadena alimentaria, cooperativas, coste efectivo.

\section{Introducción. La singularidad de la relación del socio con su cooperativa}

La oportunidad de la presente comunicación viene motivada por la publicación del Proyecto de Ley (en adelante Proyecto de Ley o PLLCA) por el que se modifica la Ley 12/2013, de 2 de agosto, de medidas para mejorar el funcionamiento de la cadena alimentaria (en adelante Ley de Cadena Alimentaria o LCA). Tanto la Ley como el Proyecto de Ley regulan diferentes aspectos, en materia de cadena alimentaria, que afectan a las sociedades cooperativas, planteando diferentes interrogantes que pueden generarles un perjuicio si no se resuelven adecuadamente. Concretamente, nos estamos refiriendo a la necesidad de determinar un procedimiento para calcular el valor del producto entregado por parte del socio a la cooperativa (art. 1.4 PLLCA por el que se modifica el art. 8 LCA) y la obligatoriedad de abonar el coste efectivo de producción al operador inmediatamente anterior, en este caso de la cooperativa al socio (art. 12 ter LCA). De manera que, la presente comunicación se centrará en analizar estas disposiciones, con el objetivo de tratar de aportar soluciones ante las diferentes incógnitas planteadas.

El primero de los aspectos objeto de análisis es el relativo a la determinación del valor del producto entregado. La necesidad de determinar este valor se debe a la nueva redacción propuesta por el Proyecto de Ley, que permite eximir a las cooperativas de la obligatoriedad de formalizar por escrito un contrato alimentario individualizado con cada socio por cada entrega de fruta realizada, siempre y cuando sus Estatutos sociales establezcan, con anterioridad a la entrega del producto, un procedimiento de determinación "del valor del producto entregado por sus socios y el calendario de liquidación y estos sean conocidos por los socios", exigiéndose, para ello, una notificación fehaciente a los interesados "que será incluida en el acuerdo y será aprobado por el órgano de gobierno correspondiente".

La configuración de esta exención viene, además, justificada por el propio Proyecto de Ley al considerar que las entregas de productos de los socios a su cooperativa no se consideran relaciones de carácter comercial (art. 1.1 PLLCA por el que se modificada el art. 2 LCA). Esta interpretación coincide con la otorgada por la doctrina especializada en materia de cooperativas que considera que la relación entre el socio de una cooperativa y la propia cooperativa, "no es una relación comercial sino societaria e interna". Por lo tanto, a diferencia de las sociedades de capital donde la entrega de fruta sí se considera una relación comercial donde sí se exige la formalización del contrato por escrito, en las cooperativas, dado que se está ante una relación de carácter societario e interno, resulta adecuado exigir que las operaciones relativas a los contratos alimentarios se formalicen a través de documentos de índole societaria como, por ejemplo, los Estatutos y los acuerdos sociales (Vargas Vasserot, 2019). 


\section{2.- La dificultad en la estimación ex ante del valor de las entregas del socio.}

Ahora bien, esta adecuada disposición que exime a las cooperativas de la obligatoriedad de la formalización de un contrato alimentario plantea un interrogante relativo a la necesidad de determinar el valor del producto entregado por los socios y el calendario de liquidación de la cooperativa con anterioridad a la entrega del producto por parte del socio. La falta de concreción de la determinación del valor del producto hace necesaria la búsqueda de soluciones. En este sentido, la Ley de cadena alimentaria, para el caso de configurar un contrato alimentario, establece, determinadas pautas para determinar el precio del contrato (art. 9.1.c) LCA). Concretamente, para la fijación del precio, el legislador contempla una serie de costes, donde necesariamente, deberá concurrir el coste efectivo de producción que ha soportado quien entrega el producto. Por lo tanto, podemos extraer que el valor del producto entregado por cada socio a la cooperativa deberá ser como mínimo su coste efectivo de producción.

Esta aparente solución, no es más que otro obstáculo en tan complejo y enrevesado laberinto, toda vez que las pautas otorgadas por el legislador para calcular el coste efectivo de producción son escasas. En el caso que nos concierne, cuando se trate de explotaciones agrarias, el legislador establece que se deberán tener en consideración "factores tales como las semillas y plantas de vivero, fertilizantes, pesticidas, combustibles y energía, maquinaria, reparaciones, costes de riego, alimentos para los animales, gastos veterinarios, trabajos contratados o mano de obra asalariada" (art. 9.1. c) LCA). Por lo tanto, el legislador parece abogar por la configuración de los costes efectivos de producción mediante los costes variables (García Azcarate, 2021); sin embargo, se considera necesario añadir a los costes variables los costes fijos y los costes de oportunidad. Como costes fijos se pueden considerar, entre otros, los costes por amortización de elementos de inmovilizado, los impuestos o el coste del seguro de la explotación. Como costes de oportunidad sufridos como consecuencia de llevar a cabo su explotación pueden distinguirse, entre otros, el coste de la renta de la tierra o los intereses financieros de la explotación dejados de percibir (Fernández-Zamudio, 2021). Por lo tanto, la determinación del coste efectivo podría resumirse como la suma de los costes fijos más los costes variables y de oportunidad.

A pesar de todo, consideremos que esta propuesta de metodología de cálculo ex ante del coste de producción efectivo tiene una muy complicada extrapolación a una cooperativa de comercialización agraria, principalmente, porque las sociedades cooperativas tradicionalmente se han caracterizado por realizar la determinación de su coste efectivo de producción de manera ex post, es decir, una vez han recibido toda la fruta de sus socios, empiezan a determinar los costes y puede empezar a fijar los precios de liquidación, por el procedimiento de márgenes brutos o de costes estándares (Juliá Igual, 1985). Si se optara por una determinación del coste efectivo de producción de forma ex ante, se liquidarían a los socios unos precios que indirectamente beneficiaran a aquellos más ineficientes que verían como se les abonaría la totalidad de los costes incurridos, y probablemente, en muchas ocasiones, dada la evolución de precios del mercado en escenarios de precios bajos, llevaría a cuantiosas pérdidas a la cooperativa y colisionaría con el procedimiento de valoración de la entrega de las cosechas de los socios a la cooperativa establecida en la Ley 20/1990 de Régimen Fiscal de Cooperativas (art. 15), que claramente les aboca a su fijación ex post (Juliá, Server 1996). Ello implica, que, en ningún caso, los precios a liquidar al socio puedan exceder de la cantidad resultante de deducir al valor de las ventas de los productos de los socios, el precio de mercado alcanzado por la cooperativa y los gastos incurridos conforme a las normas contables y fiscales establecidas.

En nuestra opinión, consideramos necesaria la determinación de un coste efectivo que fuera acorde a las necesidades y características de cada cooperativa y que, a su vez, sea compatible con la legislación sustantiva y fiscal de este tipo de sociedades. Lamentablemente, ello no es tarea sencilla dadas las particularidades de cada zona productiva, variedad vegetal, estructura, tipo de explotación y las impredecibles consecuencias de la meteorología. Por ello, consideramos necesario que la Ley contemple un criterio que habilite el cálculo del coste efectivo de producción, proponiéndose como posibles alternativas, la fijación de un precio mínimo propuesto por el Ministerio atendiendo a las particularidades de cada zona de producción o, por el contrario, la habilitación a las cooperativas para que cada campaña calculen un coste medio de referencia de todos sus socios, donde se integren todos los costes incurridos por todos ellos en las 3 últimas campañas, incluyendo al menos costes fijos y variables y añadiendo al coste resultante un valor determinado para minimizar el posible riesgo existente.

A esta situación de inseguridad jurídica, el legislador, con el objetivo de evitar la destrucción de valor en la cadena, exige que cada operador formalice por escrito que ha pagado al operador inmediatamente anterior un precio que, como mínimo, iguale su coste efectivo de producción, estando este último conforme con la operación (art. 12 ter LCA). Este quizás sea, junto con la determinación del coste efectivo de producción, el elemento de mayor riesgo para la cooperativa debido a la dificultad que plantea cubrir todos los costes efectivos de producción de todos sus socios y el riesgo que asume la cooperativa de ser denunciada por sus socios si no cumple con tal obligación. En este sentido, consideramos necesario abogar por la misma 
interpretación que ha llevado al legislador a excluir de la necesidad de formalizar un contrato alimentario entre los socios y la cooperativa dado el carácter societario e interno de su relación -sin duda existe una relación mutualista entre los socios y la cooperativa-. Consideramos que esta exigencia dificulta considerablemente el funcionamiento de la cooperativa, por lo que, o bien, el legislador establece un criterio de determinación del coste efectivo de producción que evite el inicio de procedimientos de infracción contra la cooperativa por falta del cumplimiento del pago del coste efectivo; o se excluye de la aplicación de esta disposición a las sociedades cooperativas, toda vez que este precepto está pensado para ser de aplicación a las sociedades de capital y a la gran distribución. Por tanto, hay que abogar por que no se aplique esta obligación a las compras que la cooperativa de producción realiza a sus socios, dado que se trata de la actividad cooperativizada y la cooperativa actúa ahí sin ánimo de lucro.

\section{3.- Conclusión}

Pensamos que tanto la Ley de cadena alimentaria como su proyecto de Ley son muy importantes y necesarios para el sector agroalimentario y cooperativo. Sin embargo, a nuestro modo de ver, el Proyecto de Ley de cadena alimentaria requiere de una profunda reconsideración, sobre todo, en aquellas disposiciones que afectan a las cooperativas. Cada vez más se realiza un tratamiento casi unitario de las sociedades cooperativas y a las sociedades de capital en su condición de agentes que actúan en un mercado global y competitivo, sin embargo, no podemos perder de vista las especialidades de las sociedades cooperativas que, en ocasiones, impiden un tratamiento uniforme de ambas realidades. Por ello, como alternativa a la redacción propuesta en el Proyecto de Ley de cadena alimentaria, consideramos oportuno abogar por una regulación ad hoc sobre aspectos de las cooperativas en materia de cadena alimentaria donde se aborde con mayor precisión los extremos relativos a su participación, especialmente, la determinación del coste efectivo de producción.

Es claro que las enormes asimetrías existentes en la cadena de valor agroalimentaria y los desajustes temporales entre la oferta y demanda agroalimentaria en muchas producciones, han propiciado sin duda situaciones desfavorables en el proceso de formación de precios y de la distribución del valor a lo largo de la cadena alimentaria en perjuicio de uno de los eslabones más débiles que es el productor agrario, en general, muy atomizado y con un escaso poder negociador (Colom, Florensa, 2021), lo que justifica que tradicionalmente se haya ayudado a facilitar los procesos de agrupamiento de su oferta mediante organizaciones de productores y, en particular, de sus cooperativas de comercialización agraria, dejándolas a estas organizaciones y empresas bajo la excepción de los mecanismos del derecho de la competencia con un trato que atiende a la consideración de su realidad y marco regulatorio sustantivo diferente del de las sociedades de capital, y al hecho de que con su acción se pretende la defensa de la renta de los productores agrarios mediante una mejor defensa y estabilidad de los precios, que, como es sabido, constituye uno de los objetivos históricos de la PAC (véase, entre otros, Carbajo Cascón, 2020; Tato Plaza et al, 2019; Viciano Pastor, 2019; Arias Varona, 2019; Guillem Carrau, 2014).

No podemos olvidar tampoco que," la UE desde hace ya años se viene pronunciando a favor de reequilibrar al productor en la cadena de valor alimentaria, con objeto de corregir las grandes asimetrías que en la misma se dan entre los productores agrarios y los operadores con los que estos se relacionan, tal y como señalaba en 2009 en su informe ante el Parlamento Europeo la eurodiputada Katerina Batzeli" (Meliá, Carnicer, Juliá, 2018). Es por ello, que podemos concluir, que se trata de un tema que hay que resolver bien, atendiendo a sus especiales características societaria e interés social, y que desde luego el Proyecto de Ley en su actual redacción no da una respuesta adecuada y más bien puede generar inseguridad jurídica como indican voces autorizadas y conocedoras de este sector y de las organizaciones cooperativas, a las que hemos entrevistado29, y como prueba el hecho de que la mayor parte de las más de 340 enmiendas presentadas en su tramitación en las Cortes al citado Proyecto de Ley por los representantes de los distintos grupos parlamentarios se hayan centrado en estos temas.

Por último, si bien es cierto que se trata de una norma que persigue un loable fin, cual es evitar la destrucción de valor en la cadena alimentaria, defendiendo los intereses de los productores agrarios, como eslabón más

${ }^{29}$ Los autores de la presente comunicación quieren agradecer la colaboración en este trabajo a los representantes y expertos del sector con quien se entrevistaron para conocer su posición y visión sobre este tema. Cirilo Arlandis. Vicepresidente de Cooperativas Agroalimentarias de España, y Presidente de Cooperativas Agroalimentarias de la Comunidad Valenciana. Enrique Belles. Director general de Cooperativas agroalimentarias de la Comunidad Valenciana y Ex presidente de la interprofesional citrícola española INTERCITRUS. Francisco Borras. Senior Advisory Consultant. Ex Subdirector General del grupo cooperativo ANECOOP. 
débil, al tratar de garantizar un precio por sus productos que cubra sus costes efectivos de producción, puede que, de no resultar garantizado esto al resto de operadores inmediatos en la cadena, nos conduzca a un especie de oxímoron, ya que algunos operadores, con el objetivo de poder competir, buscaran adquirir productos de países terceros, tratando de poder suministrarse en momentos de precios de mercados a la baja, en el que no fuera posible la adquisición de productos a un precio que cubra el coste efectivo de sus productores y suministradores locales.

\section{4.- Referencias bibliográficas}

Arias Varona, F. J., (2019). "La armonización europea de la regulación de la cadena alimentaria", $L a L E Y$ mercantil, N. ${ }^{\circ} 60$.

Carbajo Cascón, F., (2020). "Las exenciones agrícolas en el difícil equilibrio entre política agraria común y derecho de la competencia en la Unión Europea", ADI, N. ${ }^{\circ} 40$, pp. 31-54.

Colom, A., Florensa R.M (Dirs.), (2021). Cooperativismo agroalimentario y las OPFH. Una panorámica mundial y la realidad actual europea y española, Aranzadi, Cizur Menor.

Fernández-Zamudio, M. A. (2021). "La, citricultura valenciana, la evolución de sus costes de producción e insumos que los determinan”, Levante agrícola, Núm. 455, 1er Trimestre, pp. 57-65

García Azcárate, T. (2021) "Cadena alimentaria y derecho de la competencia”, Distribución y Consumo, Año 31, N. $^{\circ}$ 165, Vol. 1, pp. 34-41.

González Castilla, F., Ruiz Peris, J. I. (Dirs.) (2016), Estudios sobre el régimen jurídico de la cadena de distribución agroalimentaria, Marcial Pons, Madrid.

Guillem Carrau, J. (2014), "Política agraria común y Derecho de la competencia", Revista de Derecho de la Unión Europea, núm. 26, pp. 135-166.

Juliá, J.F., (1985) "Algunos aspectos de la liquidación de cosechas a los socios de las cooperativas hortofrutícolas", Anales del INIA. Serie de Economía y Sociología Agraria. Vol. 9, pp. 115-139.

Juliá, J.F., Server, R. J. (1996), Fiscalidad de cooperativas. Teoría y práctica, Pirámide, (3ª edición), Madrid.

Herrero Velasco, J. M. (2021), "Marco regulatorio de la cadena alimentaria en España”, Distribución y Consumo, Año 31, N. ' 165, Vol. 1, pp. 5-10.

Meliá, E., Carnicer, M.P., Juliá, J.F. (2018), El gobierno de las sociedades cooperativas agroalimentarias españolas. Modelos de referencia y casos empresariales, CAJAMAR Caja Rural.

Vargas Vasserot, C., (2019) "Dictamen jurídico sobre la naturaleza jurídica de la relación mutualista en las cooperativas agroalimentarias", (inédito).

Viciano Pastor, J. (Dir.), Corberá Martínez, J., (Coord.) (2019), Retos en el sector agroalimentario valenciano en el siglo XXI. A propósito de la ley 12/2013, de 2 de agosto, de medidas para mejorar el funcionamiento de la cadena alimentaria, Tirant lo Blanch, Valencia.

Viciano Pastor, J., (2019), "Derecho de la competencia y sector agrícola: nuevas exclusiones y exenciones de la prohibición de acuerdos restrictivos de la competencia en el Reglamento 2017/2393", en Tato Plaza, A., Costas Comesaña, J., Fernández Carballo-Calero, P., Torres Pérez, F., (2019), Nuevas Tendencias en el Derecho de la Competencia y de la Propiedad Industrial II, Comares, Granada, pp. 169-180.

Tato Plaza, A., Costas Comesaña, J., Fernández Carballo-Calero, P., Torres Pérez, F., (2019), Nuevas Tendencias en el Derecho de la Competencia y de la Propiedad Industrial II, Comares, Granada. 